\title{
KAJIAN POLA TATANAN KEHIDUPAN DI KABUYUTAN TRUSMI, CIREBON
}

\author{
Sintia Dewi Wulanningrum \\ Departemen Arsitektur Fakultas Teknik Universitas Tarumanagara \\ Jl. Letjen S. Parman No. 1 Jakarta Barat \\ *Email: sintiadewe@gmail.com
}

\begin{abstract}
ABSTRAK
Seiring berkembangnya peradaban manusia yang ditandai dengan perkembangan teknologi yang semakin maju, pola kehidupan manusia mengalir mengikuti zamannya. Akan tetapi perkembangan ini, tidak mempengaruhi pola kehidupan di Kabuyutan Trusmi, yang tetap mempertahankan ajaran leluhurnya. Pola kehidupan dan aktivitas Kabuyutan Trusmi merupakan perwujudan dari kearifan lokal masyarakat Jawa Barat. Kearifan lokal ini dapat dilihat seperti pada bentuk bangunan yang ramah lingkungan, pola kehidupan sehari-hari yang menghargai alam dan penggunaan peralatan rumah tangga yang masih orisinil. Penelitian ini bertujuan untuk mengkaji pola tatanan kehidupan Kabuyutan Trusmi yang mencerminkan kearifan lokal daerah setempat. Metode yang digunakan adalah deskriptif kualitatif mengenai tatanan kehidupan Kabuyutan Trusmi. Hasil temuan penelitian adalah pola tatanan kehidupan Kabuyutan Trusmi yang masih menjaga tradisi nenek moyang, seperti bentuk bangunan yang masih tradisional, penggunaan material ramah lingkungan, pola kehidupan yang menjaga tradisi, dan penggunaan alat-alat memasak yang masih tradisional.
\end{abstract}

Kata Kunci: Pola Kehidupan, Kabuyutan Trusmi, Kearifan Lokal.

\section{PENDAHULUAN}

Kebudayaan dalam masyarakat selalu mengalami perubahan dan perubahan tersebut terjadi ketika suatu kebudayaan melakukan kontak atau hubungan dengan kebudayaan asing. Dampak globalisasi terhadap perubahan pola kehidupan masyarakat Indonesia sangatlah besar, terutama pada kebudayaan daerah yang mengalami perubahan dan tentunya perubahan kebudayaan yang terjadi saat ini tidak lepas dari peran masyarakat (Nani Tuloli, 2003).

Perwujudan kebudayaan setiap masyarakat di berbagai daerah membentuk karakteristik, ciri atau corak kedaerahannya sesuai latar sosial budaya masing-masing. Setiap produk hasil kesenian yang dihasilkan bukan semata untuk memenuhi nilai keindahan, tetapi mengandung nilai kedaerahan yang memperkaya kebudayaan di nusantara (Sulistiyani, 2013).

Dalam kesenian tradisoinal, karya seni rupa yang dicipta tidak semata untuk keindahan, sebaliknya tak ada benda pakai yang dibuat fungsional. Aspek keindahan pada produk seni bukan sekedar memuaskan mata melainkan berpadu dengan kaidah moral, adat, kepercayaan dan sebaliknya. Sehingga bermakna sekaligus indah. Oleh sebab itu kebudayaan yang tumbuh dari masyarakat merupakan pencerminan keindahan dari suatu karya masyarakat yang merupakan perpaduan dari nilai-nilai adat, moral dan kepercayaan setempat. Kebudayaan yang dihasilkan merupakan hasil dari tatanan hidup sehari-hari, yang memiliki karakteristik tertentu. (H:Iteori 15 des 16lDsDwiar's Jurnal Pengaruh Teknologi Informasi bagi Masyarakat, 2013).

Hasil dari sebuah kebudayaan berupa produk-produk karya seni. Produk-produk karya seni yang dapat dilihat dikehidupan sehari-hari misalnya ornamen hias, pola kehidupan dan bentuk bangunan.

Tujuan dari penelitian ini adalah untuk mengkaji pola tatanan kehidupan Kabuyutan Trusmi melalui bentuk bangunan, perlatan yang digunakan dan pola kehidupan sehari-hari. 
Rumusan masalah mengenai bagaimana pola tatanan kehidupan kabuyutan trusmi, dilihat dari aktivitas sehari-hari, bentuk bangunan dan peralatan yang digunakan. seperti pada bentuk bangunan yang ramah lingkungan, pola kehidupan sehari-hari yang menghargai alam dan penggunaan peralatan rumah tangga yang masih orisinil

\section{KAJIAN LITERATUR}

Kabuyutan dalam bahasa Sunda berarti barang atau tempat kuno yang tidak boleh diperlakukan sembarangan karena bisa menimbulkan akibat yang tidak diinginkan. Para ahli sejarah menganggap tempat ini sangat penting dikarenakan di sini tersimpan berbagai peninggalan sejarah yang masih tetap terpelihara samapi sekarang. Oleh sebab itu pemerintah menetapkannya sebagai cagar budaya. Istilah Kabuyutan dalam agama Sunda setidakny a sudah ada pada awal abad ke-11 M.

Prasasti Sanghyang Tapak yang dibuat kira-kira tahun 1006-1016 M, menerangkan bahwa Prabu Sri Jayabupati (selaku Raja Sunda) sudah menetapkan sebagian dari wilayah walungan Sanghyang Tapak (ketika itu) selaku kabuyutan, yaitu tempat yang mempunyai pantangan yang harus dituruti oleh semua rakyatnya

(https://id.wikipedia.org/wiki/Kabuyutan, 2016).

Istilah ini terbentuk dari kata dasar buyut. Adapun kata buyut mengandung dua arti. Pertama, turunan keempat (anak dari cucu) atau leluhur keempat (orang tua dari nenek dan kakek). Kedua, pantangan atau tabu alias cadu atau pamali. Di kabuyutanlah orang-orang terpelajar itu menulis naskah, mengajarkan ilmu agama, atau memanjatkan

doa. (http://kuliahtantan.blogspot.co.id/2014/03/tugas 1ekologi-manusiakonsep-kabuyutan.html\#more, 2016).

Sebagai tempat kegiatan religius, kabuyutan kiranya memperlihatkan salah satu jejak kebudayaan Sundayana di tatar Parahyangan. Kadang-kadang tempat tersebut disebut pula mandala. Bagi para filolog, kabuyutan cenderung diartikan sebagai skriptorium, yaitu tempat membuat dan menyimpan naskah. Kabuyutan Ciburuy, di kaki Gunung Cikuray, Kecamatan Bayongbong, Kabupaten Garut, adalah salah satu contohnya. Kabuyutan ini terletak lebih kurang $20 \mathrm{~km}$ di sebelah

selatan Kota

Garut. (http://kuliahtantan.blogspot.co.id/2014/03/tugas 1 ekologi-manusiakonsep-kabuyutan.html\#more, 2016).

1. Sedikitnya terdapat 10 arti, makna atau maksud istilah kabuyutan, yaitu: Umumnya dikaitkan dengan makna utamanya sebagai tempat suci, tempat yang disucikan atau disakralkan, situs atau tempat keramat, situs atau prasasti, di (menurut) masyarakat Tatar Sunda.

2. Nama tempat suci di kawasan luar Tatar Sunda, namun orang yang menggunakannya adalah orang Sunda (lihat misalnya: penggunaan istilah "kabuyutan Majapahit" oleh Bujangga Manik, seorang sejarawan Sunda yang hidup kl. Pada abad 15-16 M.

3. Tempat-tempat suci yang dinamakan kabuyutan tersebut dapat berupa pertapaan, gunung, sungai, atau kawasan kerajaan yang secara geografis dapat dijumpai sampai di luar wilayah Jawa Barat sekalipun.

4. Berarti leluhur atau karuhun atau nenek moyang.

5. Berasal dari kata "buyut", digunakan untuk menyebut larangan, tabu, atau pantangan dari leluhur sebagaimana dalam adat masyarakat Baduy.

6. Nama lembaga pendidikan dalam sejarah Tatar Sunda yang berlangsung sampai sebelum periode pesantren.

7. Nama pedang pusaka kerajaan di yang terdapat di museum Sumedang dan diperlihatkan kepada masyarakat luas pada upacara tertentu.

8. Dalam kepercayaan masyarakat Bali, bermakna leluhur yang berdiam di Kahiyangan; atau nama suatu jenis penyakit.

9. Nama desa-desa di Jawa di masa lalu dan "Buyut" atau "Dhari" adalah nama pemimpin desa (kabuyutan) tersebut.

10.Berarti musuh yang harus dijauhi atau musuh abadi (musuh bebuyutan).

Situs kabuyutan dibeberapa tempat memiliki bentuk materi fisik yang berbeda-beda. Situs kabuyutan seorang tokoh besar biasanya dipagari oleh dinding pada sebuah area, bahkan situs kabuyutan paling tinggi tingkatanya memiliki sejumlah bangunan pendukung yang membentuk kompleks di dalam area situs dan dikelola oleh sejumlah kuncen yang khusus tinggal di dalam area serta dikelilinhi oleh area pemakaman.contoh situs kabuyutan yang tinggi tingkatanya di situs $\mathrm{Ki}$ Buyut Trumsi di 
kecamatan Plered dan situs Astana Gunung Jati di Kecamatan Gunung Jati (Mujabuddawat, M., 2013).

Kearifan lokal adalah segala bentuk kebijaksanaan yang didasari oleh nilai-nilai kebaikan yang dipercaya, diterapkan dan senantiasa dijaga keberlangsungannya dalam kurung waktu yang cukup lama (secara turuntemurun) oleh sekelompok orang dalam lingkungan atau wilayah tertentu yang menjadi tempat tinggal mereka. (Indriastjario, Adji, 2013).

Hal tersebut dapat terwujud dalam beberapa bentuk seperti: pola pikir masyarakat yang berbudi pekerti, perasaan yang dalam terhadap tanah kelahiran, bentuk perangai atau tabiat masyarakat, filosofi hidup masyarakat tertentu yang mendarah daging dan keinginan besar untuk tetap menjalankan adat atau tradisi yang telah lama diikuti secara turun temurun.

\section{METODE PENELITIAN}

Metode penelitian yang digunakan adalah deskriptif kualitatif. Metode kualitatif digunakan untuk mengetahui gambaran umum pola tananan kehidupan di Kabuyutan Trusmi, Cirebon. Pengumpulan data yang digunakan melalui data primer dan sekunder. Data primer diperoleh dengan cara observasi lapangan dan dokumentasi mengenai kajian pola tatanan kehidupan masyarakat di kabuyutan trusmi. Data sekunder diperoleh melalui, jurnal, buku dan data internet yang relevan .Setelah data primer dan data sekunder terkumpul, kemudian dilakukan analisa mengenai pola tatanan kehidupan yang mencakup pola kehidupan, bentuk bangunan yang dan penggunaan peralatan rumah tangga sehari-hari.

\section{HASIL DAN PEMBAHASAN}

Kabuyutan Trusmi merupakan komplek pemakaman yang terdiri dari beberapa bangunan yang memiliki fungsi masing-masing yang berlokasi di Plered, Cirebon. Kabuyutan Trusmi merupakan situs bersejarah peninggalan kebudayaan Islam Jawa (http://www.thearoengbinangproject.com/maka m-ki-buyut-trusmi-cirebon/, 2016).

Kabuyutan Trusmi dikelilingi oleh dinding tembok batu bata merah. Pendiri dari Kabuyutan Trusmi adalah Ki Buyut merupakan putra pertama Parbu Siliwangi, yang memiliki nama asli Pangeran Walangsungsang atau Pangeran Cakrabuana, yang merupakan pendidri kerajaan Cirebon. Setelah Ki Buyut menyerahkan Keraton Kasepuhan ke Sunan Gunung Jati, kemudian Ki Buyut pindah ke daerah Trusmi pada tahun 1470. Pada tahun 1481, Ki Buyut mendirikan komplek Kabuyutan Trusmi.

Bangunan yang terdapat di dalam komplek kabuyutan Trusmi antara lain, bale paseban, bale pakuncen, pendopo, pewadonan, masjid, tempat wudhu, ruang peziarah, pawestren, jinem kulon, jinem wetan, bale pesalinan, pakulahan dan gerbang kori agung. Sebagian besar bangunan di kabuyutan memiliki pintu yang rendah. Sesuai dengan filosofi orang Jawa, ketika kita masuk ke dalam bangunan harus menunduk tau membungkuk yang menunjukkan rasa hormat terhadap pemilik rumah atau bangunan (Gambar 1).

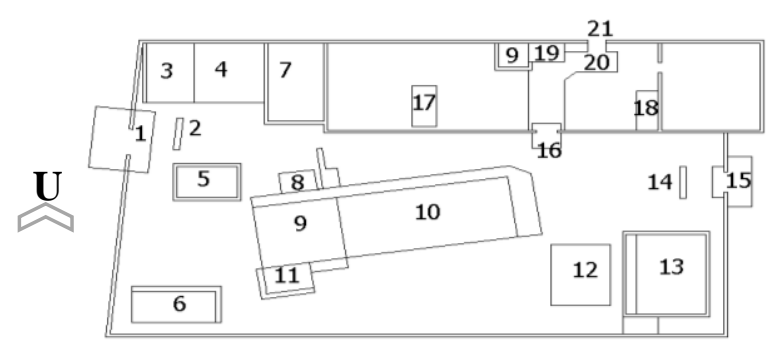

Gambar 1. Denah Sebaran Ruang Komplessitas Sumber: Mujabuddawat, M., 2013 dengan olahan penulis

Keterangan:

1. Gerbang kori agung

2. Kuta hijab

3. Bale pakuncen

4. Bale paseban

5. Pendopo

6. Pewadonan

7. Pawon

8. Tempat wudhu

9. Ruang utama masjid

10. Serambi masjid

11. Pawestren

12. Witana

13. Pekulahan

14. Kuta hijab

15. Gerbang kori agung

16. Gerbang kori agung

17. Jinem kulon

18. Jinem wetan

19. Bale pesalinan

20. Ruang petilasan

21. Gerbang kori agung 
Pola kehidupan dan aktivitas Kabuyutan Trusmi merupakan perwujudan dari kearifan lokal masyarakat Jawa Barat. Kearifan lokal ini dapat dilihat seperti pada bentuk bangunan yang ramah lingkungan, pola kehidupan sehari-hari yang menghargai alam dan penggunaan peralatan rumah tangga yang masih orisinil. Pola kehidupan dan aktivitas Kabuyutan Trusmi merupakan perwujudan dari kearifan lokal masyarakat Jawa Barat. Kearifan lokal ini dapat dilihat seperti pada bentuk bangunan yang ramah lingkungan, pola kehidupan sehari-hari yang menghargai alam dan penggunaan peralatan rumah tangga yang masih orisini.

Di dalam komplek Kabuyutan Trusmi terdapat beberapa ruang yang digunakan sebagai aktivitas sehari-hari oleh kuncen dan pewaris kabuyutan. Seperti pendopo di Jawa, fungsi Pendopo di komplek kabuyutan Trusmi digunakan sebagai tempat untuk menerima tamu serta untuk tempat berbincang-bincang. Atap pendopo berbahan sirap yang serta tidak terdapat dinding pada bangunan ini. Terdapat empat kolom, yang terbuat dari kayu yang menyangga atap pendopo. Semua atap bangunan di komplek kabuyutan ini memakai sirap yang merupakan perwujudan dari kearifan lokal (Gambar 2).

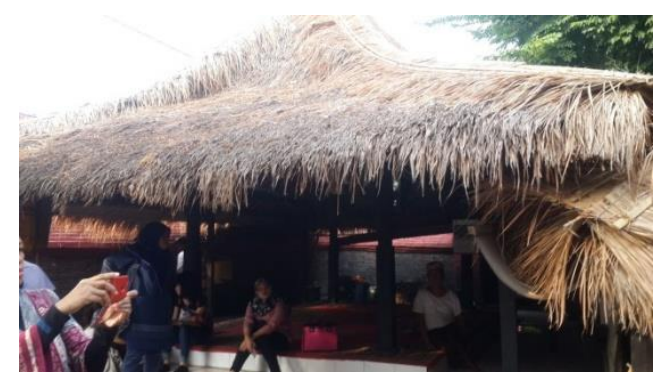

Gambar 2. Pendopo

Masjid di komplek ini memiliki tinggi ruang 240 meter dan tinggi bangunan 500 meter. Bentuk atap tumpang dengan bahan sirap. Bangunan masjid terdiri dari sermbi masjid, ruang utama atau ruang solat, ruang solat kaum wanita atau pawestren, tempat wudhu dan mimbar (http://www.cirebonpos.com/masjidtrusmi-syarat-sejarah-penyebaran-islam-

cirebon/, 2015). Pawestrean digunakan sebagai tempat solat kaum wanita. Bangunan ini menempel dengan masjid. Berdasarkan konsepnya, sejumlah masjid tua di Jawa, serambi kiri (selatan) dibuat agak tertutup untuk sholat kaum wanita. Ruanganan ini menyambung dengan bangunan masjid dengan ukuran pendek. (Mujabuddawat, M., 2013). Atap bangunan berbahan sirap dengan tinggi bangunan 250 meter dan tinggi bangunan 350 meter (Gambar 3).

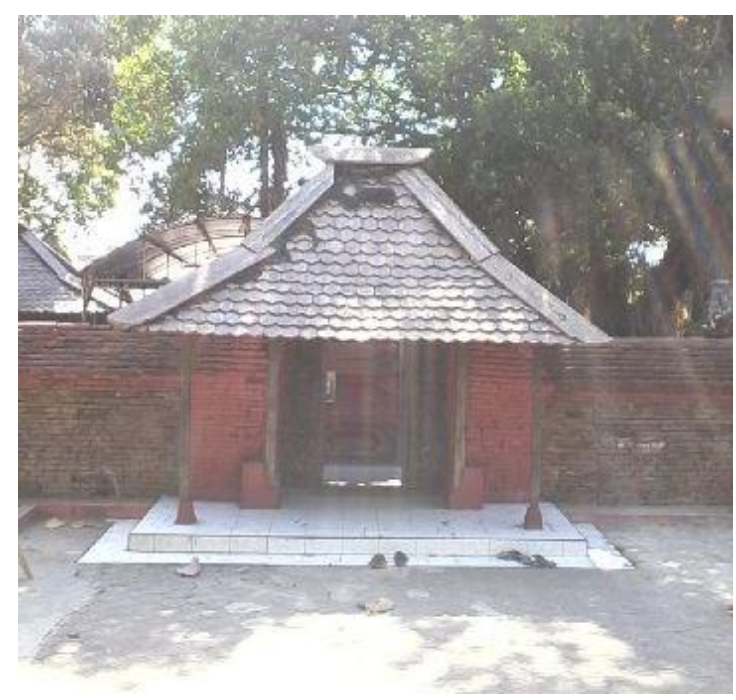

Gambar 3. Masjid di Kabuyutan Trusmi

Pewadonan merupakan ruang khusus kaum wanita yang digunakan untuk beristirahat. Pewadonan berasal dari kata wadon, dalam bahasa Jawa yang berati wanita.

Pewadonan memiliki atap sirap dengan tinggi ruang 250 meter dan tinggi bangunan 350 meter. Dinding pewadonan terbuat dari dinding kayu yang dilapisi anyaman bambu (Gambar 4).

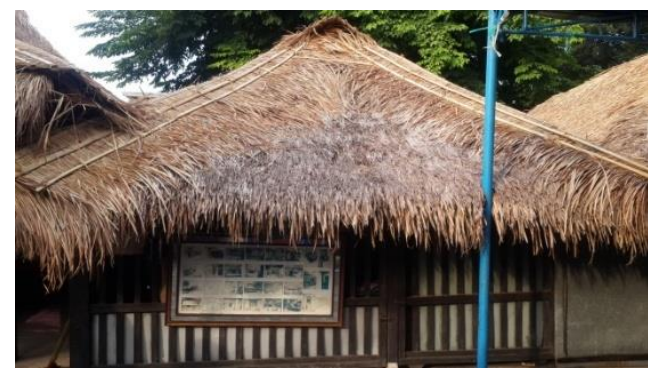

Gambar 4. Pawadonan

Komplek makam di Kabuyutan Trusmi, tersebar di beberapa sisi (Gambar 5). Pada saat memasuki komplek pemakaman, terdapat gapura rendah setinggi pinggang orang dewasa. Ketika melewatinya, orang atau peziarah harus membungkuk, hal tersebut merupakan cara untuk memberikan penghormatan pada penghuni kubur. Di dekat pemakaman terdapat Bale peziarah. Bale peziarah merupakan bangunan yang digunakan untuk tempat bersistirahat dan tempat menunggu bagi peziarah. Atap bangunan ini berbentuk tajuk dengan susunan sirap, tinggi bangunan 270 
meter dan tinggi bangunan 290 meter. Dinding bale pesalinan terbuat dari bahan kayu serta anyaman bambu. Pada sisi samping bawah bale pesalinan, setengah dinding yang digunakan adalah dinding bata (Gambar 6).

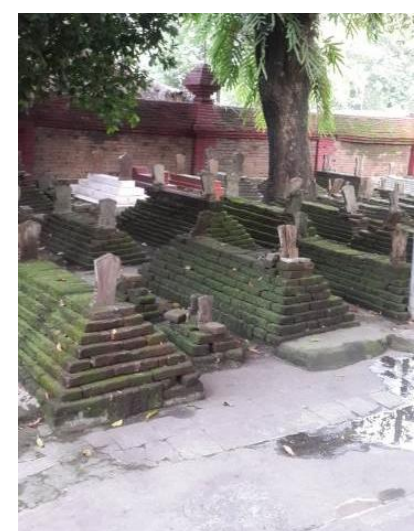

Gambar 5. Komplek Pemakaman

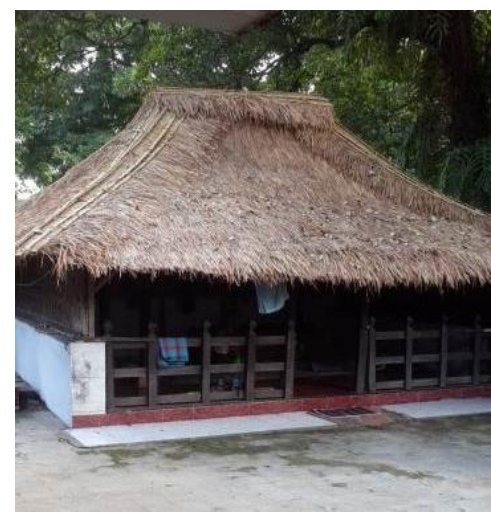

Gambar 6. Bale Peziarah

Tepat di pintu masuk utama, terdapat gerbang kori agung atau gerbang masuk situs. Gerbang kori agung merupakan gerbang dalam khasanah kebudayaan islam di Indonesia pada zaman madya dengan ciri-ciri fisik memiliki atap, berdaun pintu serta ukurannya pendek sehingga orang harus menunduk untuk melewatinya (Gambar 7).

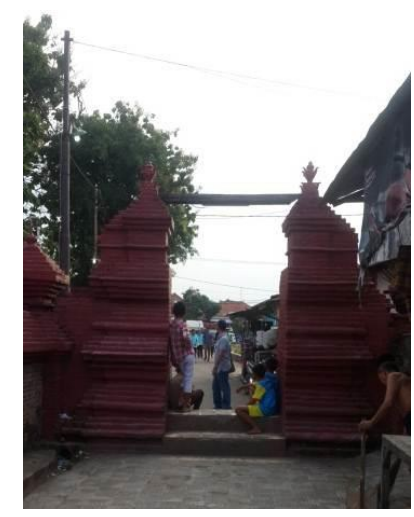

Gambar 7. Gerbang Kori Agung
Pekulahan adalah suatu sumber air pertama yang ada di muka bumi yang menurut kepercayaan dapat mengobati orang sakit dan menyucikan badan dari segala hal, baik gaib dan yang nyata (Gambar 8). Sedangkan Witanan sendiri, adalah tanah pertama yang ada dimuka bumi.Adanya Pekulahan (Sumber Air Pertama) dan Witana (Tanah Pertama) menjadi bukti akan sejarah panjang perjuangan dalam menyebarkan Islam di Cirebon, khususnya di Trusmi. Saat ini, fungsi pekulahan telah mengalami perubahan yaitu sebagai kolam bermain anak-anak sekitar kabuyutan Trusmi.

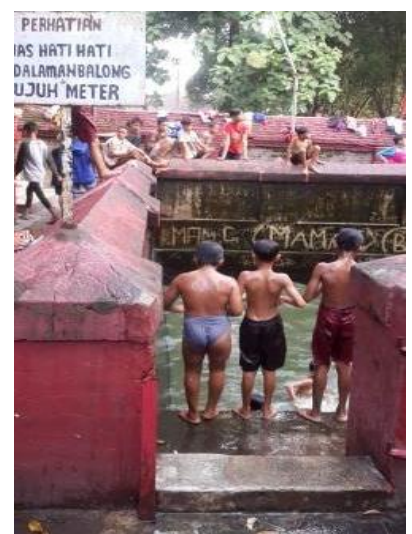

Gambar 8. Pekulahan

Di kabuyutan Trusmi terdapat dapur atau pawon yang yang terdiri dari ruang memasak dan persiapan. Ruang memasak dibuat terpisah dari ruang persiapan. Pawon digunakan untuk memasak makanan, khususnya pada upacara keagamaan dan upacara adat. Ketika akan masuk ke dapur, orang akan menunduk dikarenakan tinggi dapur yang cukup rendah. Ruang persiapan berada di sisi utara sedangkan ruang memasak berada di sisi barat. Ruang persiapan digunakan untuk meletakkan makanan yang telah selesai dimasak. sedangkan ruang memasak digunakan untuk memasak makanan serta mencuci bahan makanan dan mencuci alat masak (Gambar 9).

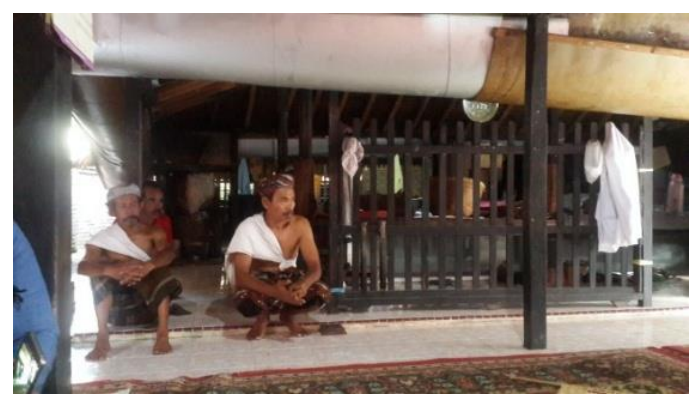

Gambar 9. Ruang Persiapan 
Di ruang persiapan sebagian besar peralatan rumah tangga yang digunakan masih tradisional seperti tudung saji (Gambar 10) yang terbuat dari kayu, tempat makanan yang terbuat dari anyaman bambu, tempat nasi dari bambu. Setelah masakan selesai dimasak akan dilettakan di meja besar yang terbuat dari kayu yang dilapisi anyaman bambu.

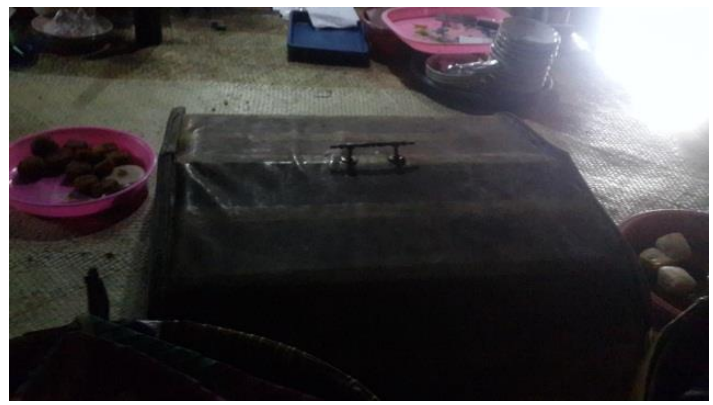

Gambar 10.Tudung saji

Sebagian besar peralatan memasak yang digunakan masih tradisional yaitu dari batok kelapa yang telah dikeringkan tanpa menggunakan kompor yang modern. Hal ini menunjukkan bahwa dalam kehidupan seharihari di Kabuyutan Trusmi masih menggunakan cara tradisional tanpa mengikuti perkembangan teknologi yang ada saat ini. Berdasarkan peralatan masak serta cara memasak di kabuyutan Trumsi mencerminkan kearifan lokal, dimana penggunaan alat-alat modern tidak mendominasi kehidupan. Hal ini tercermin dari penggunaan alat memasak dari tanah liat dan kayu (Gambar 11, dan 12).

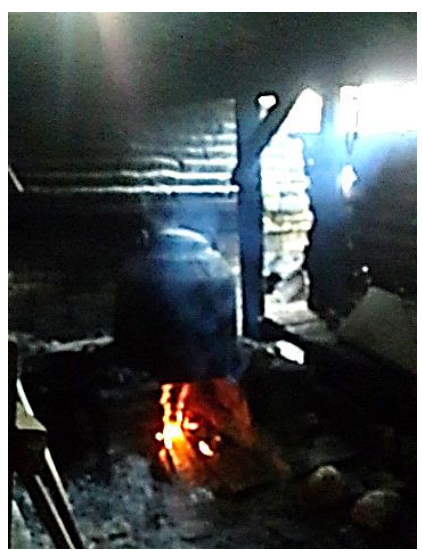

Gambar 11. Perapian Untuk Memasak

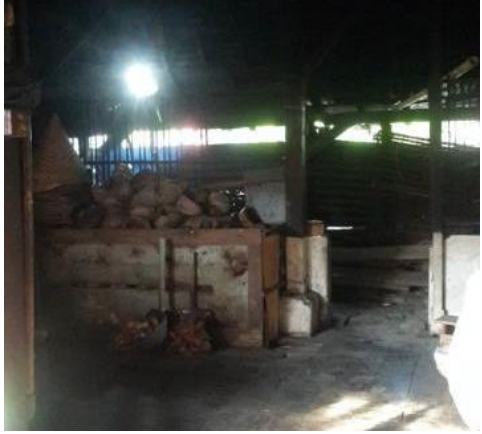

Gambar 12. Batok Kelapa yang Digunakan untuk Memasak

Pakaian adat dari Kabuyutan Trusmi yaitu menggunakan pakaian khas, dengan atasan putih (kain yang disematkan di badan) dan bawahan kain sarung atau jarik serta memakai iket kepala. Hal ini merupakan tradisi dari leluhur turun menurun yang masih dijaga sampai sekarang. Pakaian ini khusus di gunakan untuk kaum pria (Gambar 13).

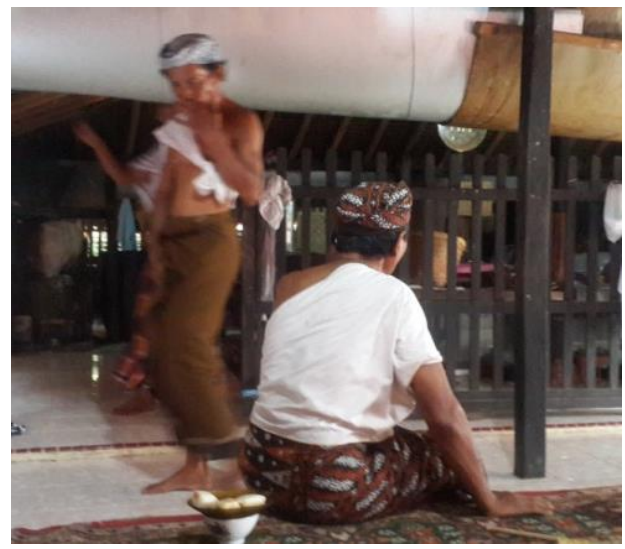

Gambar 13. Pakaian Khas Kabuyutan Trusmi

Penggantian penutup ata sirap separuh bangunan atau memayu dilakukan setiap empat tahun sekali. Penggantian atap dari anyaman daun kelapa atau welit dilakukan setiap tahun pada 25 maulud. Memayu memiliki tujuan untuk memperbaharui sifat-sifat manusi dari sifat lama yang kurang baik menjadi sifat baru yang lebih baik. Pada acara penggantian sirap mengalir sumbangan dari warga berupa makanan, tenaga dan uang (https://esubijono.wordpress.com/page/5/, 2013) (Gambar 14).

Acara pergantian sirap merupakan pesta rakyat dan ketika malam hari diadakan tahlilan disertai shalawat brai (kesenian Bayalangu) yang diiringi alat musik gemblung (sejenis rebana), kendana dan krecek, pertunjukkan wayang kulit. Selain itu terdapat cara arak- 
arakan kirab 14 tombak pusaka Ki Buyut, serta hasil bumi . Dalam acara ini ditampilkan tarian babak Yoso dan tari agung.

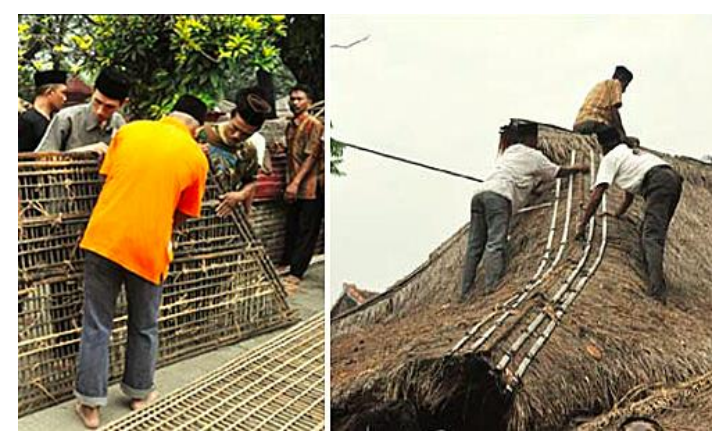

Gambar 14. Penggantian Sirap

Sumber: http://esubijono.wordpress.com, 2013

\section{KESIMPULAN}

Kabuyutan Trusmi merupakan situs bangunan bersejarah peninggalan kebudayaan Islam. Kabuyutan ini merupakan komplek pemakaman yang memiliki bangunan pendukung lainnya yang dikelilingi oleh dinding tembok bata merah. Bentuk bangunan serta bahan bangunan merupakan cermin dari kearifan lokal. Kearifan lokal di tunjukkan dengan bentuk atap tajuk; pemakain bahan penutup atap sirap, serta sebagian besar penutup dinding dari kayu serta anyaman bambu. Pola kehidupan sehari-hari di Kabuyutan yang mencerminkan kearifan lokal adalah penggunaan peralatan memasak yang masih menggunakan cara leluhur dahulu seperti batok kelapa untuk memasak, penggunaan alat memasak dari anyaman bambu dan tanah liat; masih mempertahankan upacara adat seperti acara keagaman, Memayu dan arak-arakan dimana dalam setiap acara diselingi kesenian tradisional seperti tari-tarian dan kesenian wayang. Selain itu pada saat berada di Kabuyutan Trusmi, juri kunci serta keturunan ki Buyut memakai pakaian khas dari penutup kepala "iket ", kain putih serta pakaian bawah yaitu sarung atau jarik.

\section{Daftar Pustaka}

Tulolli, Nani dkk. 2003. Dialog Budaya Wahana Pelestarian dan Pengembangan.

Sulistiyani, Sintha, 2013. Kajian Visual Dan Makna Ornamen Hias Pada Bangunan
Paseban Tripanca Cigugur Kabupaten Kuningan. Jakarta: Universitas Pendidikan Indonesia.

Pengaruh Teknologi Informasi bagi Masyarakat, 2013 (H:Iteori 15 des 16\DsDwiar's Jurnal Pengaruh Teknologi Informasi bagi Masyarakat), diakses 20 Desember 2016.

Kabuyutan, 2016 (https://id.wikipedia.org/wiki/Kabuyutan) diakses 21 Desember 2016.

Konsep

Kabuyutan, 2016 (http://kuliahtantan.blogspot.co.id/2014/0 3/tugas1ekologi-manusiakonsepkabuyutan.html\#more), diakses 13 Desember 2016.

Kabuyutan Ciburuy, 2016 (https://id.wikipedia.org/wiki/Kabuyutan Ciburuy), diakses 13 Desember

Mujabuddawat,M, \& Raharjo,W., 2013. Tinjauan Arkeologis Kompleks Situs Ki Buyut Trusmi Cirebon.

Indriastjario, Adji,B, 2013.Kajian Kearifan Lokal Untuk Pengembangan Wisata Waduk Jatibarang Kota Semarang. Modul Vo.15 No.2 Juli Desember 2015.

Keramat Buyut Trusmi, Cirebon, (http://www.thearoengbinangproject.com/ makam-ki-buyut-trusmi-cirebon/) diakses 21 Desember 2016.

Masjid Trusmi Syarat Sejarah Penyebaran Islam Cirebon, 2015 (http://www.cirebonpos.com/masjidtrusmi-syarat-sejarah-penyebaran-islamcirebon/), diakses 21 Desember 2016.

Ganti Atap di Trusmi, 2013 (https://esubijono.wordpress.com/page/5/) diakses 20 Desember 2016. 